\title{
Features of structural adaptability of polymer composite coatings
}

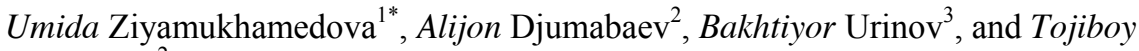 \\ Almatayev $^{2}$ \\ ${ }^{1}$ Tashkent State Transport University, Tashkent, Uzbekistan \\ ${ }^{2}$ Andijan Machine Building Institute, Andijan, Uzbekistan \\ ${ }^{3}$ Tashkent Institute of Irrigation and Agricultural Mechanization Engineers, Tashkent, Uzbekistan
}

\begin{abstract}
Coatings based on thermosetting and thermoplastic polymer binders using mechanically activated silicate fillers from local natural raw materials (from Koytash deposit), activated on a mechano-activator of wollastonite of different dispersion were investigated. The studies conducted made it possible to establish the effect of the surface roughness of the material on the cotton fiber damageability under their frictional interaction and the phenomena occurring in the polymer-cotton tribosystem, where, after the end of non-stationary friction, i.e. during the running-in period with a stable frictional interaction, the processes of formation of dynamic tribostructures continuously occur. These tribostructures provide a certain stable and minimum value of the friction force, and their destruction is compensated by their restoration, owing to information feedback.
\end{abstract}

\section{Introduction}

This paper investigates the influence of the initial and steady state roughness of coatings on the process of structural self-organization under friction.

Today, the problem of the maintenance of natural properties, particularly preventing the loss of raw cotton in the processing, which occurs during its frictional interaction with the working surfaces of metal structures of technological equipment, remains open.

Therefore, the development of models that simulate the contact interaction of the fiber mass with the surface of materials and new methods for studying the phenomena that arise in cotton processing technology is an urgent problem of composite polymer coating adaptability.

As is well known, the specificity of the frictional interaction of a highly deformable fiber mass with fibers freely mixing in the contact zone with the surface of materials leads to mechanical damage of valuable natural raw materials [1-5]. The frictional interaction of the mentioned counter-bodies lies in the inevitability of the phenomenon of fiber cohesion with the coating roughness. Under this condition, the mechanical component of the friction forces increases significantly, intensifying the damage to the fibers.

*Corresponding author: z.umida1973@yandex.ru 
Raw cotton is mechanically damaged in harvesting and processing and largely loses its natural quality; one of the main reasons for this is frictional interaction. Therefore, the process of interaction of raw cotton with materials is studied $[6,7]$ to make a rational choice of material for the manufacture of parts and working bodies of machines operating under conditions of frictional interaction with raw cotton during their unloading, loading, transportation, and drying.

Under the conditions of repeated mechanical stresses, including frictional interaction, cotton fiber is not only mechanically damaged, but various types of macro-chain destruction occur with the formation of free radicals [8], which can stabilize upon interaction with any acceptor. In this case, the possibility of a recombination reaction or chain transfer through macro-radicals or low molecular weight substances is not excluded.

This can occur when stress arises at some point during fiber deformation due to the nonuniform distribution of internal stresses; these stresses increase the critical value equal to the strength of the chemical bond between the atoms of the main chain.

As a result of chain termination, macro-radicals interact with acceptors that are always present in fibers and in the environment, for example, with oxygen. In this case, acceptors are substances capable of interacting with free radicals to form stable bonds:

$$
\begin{aligned}
& R^{0}+A B \rightarrow R A+B^{0} \\
& R^{0}+B^{0} \rightarrow R B \\
& B^{0}+B^{0} \rightarrow B B
\end{aligned}
$$

The process, ultimately, can develop according to the laws of the chain mechanism of free-radical destruction of both natural and synthetic high-molecular compounds. Therefore, when processing cotton fiber, various emulsions and lubricants are used, which play the role of a multidimensional modifier and serve simultaneously as an acceptor of free radicals and a stabilizing substance against further mechanical destruction of fibers [6, 8]. In this case, emulsions and lubricants play the role of an acceptor and improve the strength, antifriction, antistatic, and other properties of the fibers during processing $[5,8]$.

Therefore, it is of great interest to refine cotton fibers with water-soluble polymer compositions. The theoretical foundations of the synthesis and regulation of the physicochemical properties were studied in sufficient detail in [9].

Based on deep fundamental theoretical studies of working bodies operating conditions in machines and mechanisms of the cotton complex [4], and on the theory of friction and wear of materials, in particular, friction and wear of metal surfaces, metal-polymer and polymer systems, based on the fundamental laws of friction and wear of polymer and composite materials during frictional interaction with fiber mass (raw cotton), the development of antifriction polymeric materials under frictional interaction with cotton and the effect of their properties on fiber damage and wear of coatings is very relevant and urgent. This is proved by the results of the large-scale bench and applied research on the use of polymeric materials. At the same time, it is especially important to use available, and environmentally friendly technologies, such as solar treatment using direct sunlight [10] or special concenters and converters of solar radiation [11-13] in conjunction with physicochemical methods of modification of hetero-composite polymer materials $[14,15]$ at formation (curing) of coatings.

Below is a review of several publications devoted to solving various problems arising from the frictional interaction of the fiber mass with surfaces of various materials; in these articles, the mechanism of the frictional interaction of the fiber mass considering adhesion and structural parameters of composite polymer coatings under friction were not studied; so the current article is devoted to these issues. 


\section{Methods}

\subsection{Devices, equipment and materials}

To study the process under consideration, the test device shown in Figure 1 must meet the following requirements:

- the required pressure inside the cylindrical box is provided by the hydraulic system piston on the surface of the test disk. The distance from the axis of box 3 of a diameter of $50 \mathrm{~mm}$ (Figure 1) to the axis of rotation of the coated disc should be no more than $175 \mathrm{~mm}$ and no less than $25 \mathrm{~mm}$;

- the friction force is recorded by a strain gauge glued to the surface of the strain ring through a strain intensifier of the self-checking device;

- before and after each experiment, the strain system is calibrated, and the measurement result (friction force) is taken by constructing a calibration curve based on the average measurement values.

- the temperature on the surface of the test sample is measured according to the indications of thermal converters (thermos-couple) using a potentiometer;

- sliding velocity under friction is regulated by changing the rotary speed of the DC motor;

- the minimum number of cotton samples is 10 portions of $20 \pm 1 \mathrm{~g}$ each.

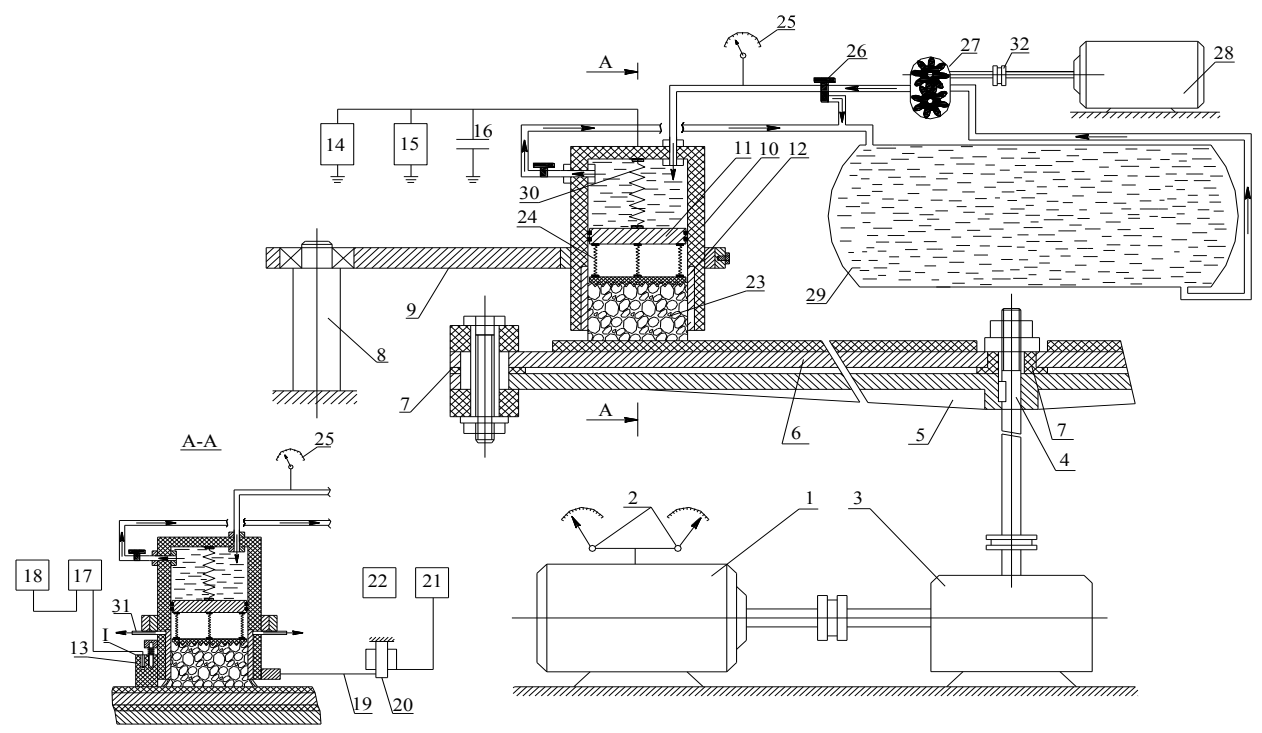

Fig.1. Disc tribometer (\# FAP00782): 1 is DC motor; 2 is fine and rough adjustment of the frequency of rotation of the electric motor; 3 is reducer; 4 is drive shaft (spindle); 5 is support disk; 6 is disc with test material; 7 is insulating gasket; 8 is axis; 9 is boom; 10 is cylindrical box; 11 is piston; 12 is aluminum gasket for collecting tribocharging potential; 13 is carbon graphite thermal measuring element; 14 is capacity meter; 15 is electrometer; 16 is additional capacity; 17 is potentiometer; 18 is thermostat; 19 is cable; 20 is strain gauge ring; 21 is strain intensifier; 22 is recording device; 23 is fiber mass; 24 is elastic element (6 pcs); 25 is pressure gauge to control pressure in the hydraulic system; 26 is pressure reducing valve; 27 is hydraulic pump; 28 is electric motor; 29 is capacity; 30 is center spring; 31 is electrical wire for potential pick-off; 32 is coupling.

The diagram of the test device - tribometer is shown in drawing A1. The test disk sample 6 is mounted on a support disk 5 driven in rotation by a DC motor 1 through a reducer 3 . The required pressure on the fiber mass is created by a piston 11 in a cylindrical 
box 10 mounted on a boom 9 , which rotates on an axis 8 under the action of friction. The friction force is recorded using 20 strain gauges glued to a strain bar, a strain intensifier 21 and an oscilloscope 22. The number of triboelectric charges is determined by measuring with a potentiometer 15 using metal electrodes 12 . The temperature in the friction zone is measured by a potentiometer 17 according to the readings of a thermoelectric converter (thermo-couple) installed in sliding carbon graphite elements 13. The sliding speed during friction is regulated by changing the rotational speed of the electric motor using regulators 2.

\subsection{Experimental part}

The test sample must be insulated from the base of a resistance of $10 \mathrm{Ohm} * \mathrm{~m}$ and a dielectric strength of $10^{4} \mathrm{~V} * \mathrm{sm}^{-1}$;

There should be a gap of $1.2 \pm 0.2 \mathrm{~mm}$ between the sample and the box. The material of the test sample is made according to Figure 3.

The roughness of the sample surface $\left(\mathrm{R}_{\mathrm{z}}\right)$ must satisfy the conditions:

$$
R_{z} \leq 0.1 d_{a v}
$$

Here $d_{a v}$ is the average fiber diameter, $\mathrm{mm}$.

The direction and shape of roughness must correspond to the technological roughness of the modeled product.

The pressure of the graphite element during sliding is $0.001-0.002 \mathrm{MPa}$;

The portions of fibrous material weighing $20 \pm 1 \mathrm{~g}$, homogeneous in moisture, impurity, and other main indices provided for this material's regulatory and technical documentation are prepared.

\section{Results and discussion}

Figure 2 shows the dependence of the friction coefficient (f) of penta plastic composite coatings on the running-in time at $R_{z} \leq 5$ and $56 \mu$ m of the initial coating surface. 


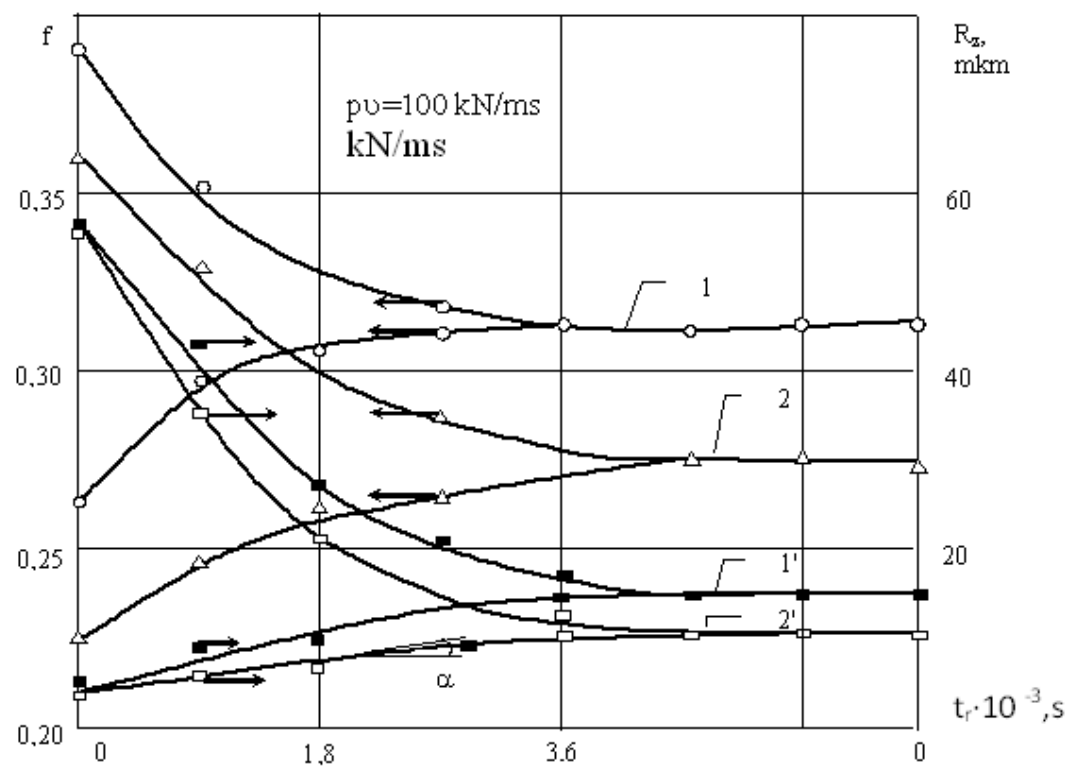

Fig.2. Dependencies of $f(1,2)$ and $R_{z}\left(1^{\prime}, 2^{\prime}\right)$ on the duration of the running-in process under frictional interaction of penta plastic composite coatings with cotton: 1,1' are Pentaplast +7 weight parts of fluoro-plastic; 2,2' are Pentaplast +20 weight parts of iron powder.

As seen from Fig. 2, after 1.5 hours of testing the cotton samples of conditioned humidity $(8.2 \%)$ and increased impurity $(18.6 \%)$, the $f$ value stabilizes at different levels for each type of composite coatings. The steady-state parameters of roughness $R_{z}$ were 16 and $11 \mu \mathrm{m}$ for compositions filled with fluoroplastic and iron powder, respectively.

It should be noted that a change in the value of the triboparameter $f$ is associated with a change in the values of the structural parameter $R_{z}$, the steady-state value of which can both increase and decrease for a particular mode of frictional interaction. The running-in time and the value of the steady-state roughness, and, hence, the value of the corresponding triboparameter $f$ are different depending on the type of coating material.

The established pattern of structural adaptability is common [5], [16-26] for the frictional interaction of materials with cotton and can be analytically described by an exponential relationship:

$$
f_{t}=f_{i}+\left(f_{s}+f_{t}\right)\left[1-e^{-k\left(t-t_{i}\right)}\right]
$$

from here, we determine the duration of the running-in process

$$
\begin{gathered}
e^{-k\left(t-t_{i}\right)}=1-\frac{f_{t}-f_{i}}{f_{s}-f_{i}} \\
-k\left(t-t_{i}\right)=\operatorname{Ln}\left(1-\frac{f_{t}-f_{i}}{f_{s}-f_{i}}\right)
\end{gathered}
$$

Then we obtain 


$$
t=t_{i}-\frac{1}{K} \operatorname{Ln} \frac{f_{s}-f_{i}}{f_{s}-f_{t}}
$$

or

$$
t=t_{i}+\frac{1}{K} \operatorname{Ln} \frac{f_{s}-f_{i}}{f_{s}-f_{t}}
$$

Where: $f_{i}$ and $f_{s}$ are the initial and steady-state values of the coefficient of friction, respectively; $t_{i}$ is the time at which the maximum of $\sigma$ is reached; $f_{t}$ is the value of the coefficient of friction at time $\mathrm{t} ; k$ is the coefficient that depends on the type and properties of the composite polymer material and on operational and technological factors.

To determine the value of $k$, we write formula (1) in the following form:

$$
f_{t}=f_{i}+\left(f_{S}-f_{i}\right)-\left(f_{S}-f_{i}\right) e^{-k\left(t-t_{i}\right)}
$$

differentiating the expression, we obtain

$$
f_{t}^{\prime}=\frac{d f_{t}}{d t}
$$

At $t=t_{i}$, we obtain

$$
k=\frac{f_{t_{i}}^{\prime}}{f_{s}-f_{i}}=\operatorname{tg} \alpha\left(f_{s}-f_{i}\right)^{-1}
$$

The physical meaning of coefficient $k$ is reduced because it shows the rate of change in the running-in process determined by the physical and mechanical properties of the material of the friction surfaces, the quality indices of raw cotton and the load-speed modes (pv) of frictional interaction. By adjusting the physical and mechanical properties and the structure of the material of friction surfaces, it is possible to control the running-in processes in the polymer-cotton system. In particular, an increase in the microhardness of the coating material and impurity content of cotton increases the period of the running-in process. The value of $f$ in the non-stationary period for coatings with a lower microhardness changes substantially both in magnitude and in the period of the running-in process determined by the numerical values of coefficient $k$. The value of $k$ for a short period of time tends to zero or to infinity with an increase in the microhardness of the coatings, providing a minimum difference between $f_{s}$ and $f_{\mathrm{i}}$ in equation (8).

The thermodynamic parameters of the frictional interaction, particularly the density of the triboelectric charge $\left(\sigma_{\mathrm{e}}\right)$, can be controlled by introducing various fillers into the composite material and refining cotton.

For an experimental study of the triboparameters of composite epoxy coatings during their frictional interaction with cotton, we chose wollastonite to concentrate as a filler with the highest yield of $3.88 ; 44.25$ and 49.6 and different dispersion values $d \leq 0,005 ; d \leq 0,05$ and $\mathrm{d} \leq 0,1 \mathrm{~mm}$, respectively. The choice of these fractions is because the finely dispersed wollastonite concentrate contains a greater amount of metals [16] and has a smaller specific 
surface area than the finely ground one, which is important to ensure the optimal structure and properties at its high economically profitable contents (50-60 weight parts).

From the experiment results (see Table 1), epoxy composite coatings filled with wollastonite have good antifriction properties during frictional interaction with cotton.

Table 1. Influence of the dispersion of wollastonite in an epoxy coating on $f$ and $\delta_{0}$ for different values of $p v$ factor

\begin{tabular}{|c|c|c|c|c|c|c|}
\hline \multirow[t]{3}{*}{ Coating types } & \multicolumn{6}{|c|}{$\begin{array}{l}\text { The value of } \sigma_{e}, f \text { and } \delta_{0} \text { (after one hour of running-in) at } \\
\text { different values of the factor } p v, \mathrm{kN} / \mathrm{ms}\end{array}$} \\
\hline & \multicolumn{3}{|c|}{50} & \multicolumn{3}{|c|}{100} \\
\hline & $\begin{array}{l}\sigma_{\mathrm{e}} \cdot 10^{5} \\
\mathrm{~K} 1 / \mathrm{m}^{2}\end{array}$ & $\mathrm{~F}$ & $\delta_{0}$ & $\begin{array}{l}\sigma_{\mathrm{e}} \cdot 10^{5} \\
\mathrm{~K} 1 / \mathrm{m}^{2}\end{array}$ & $F$ & $\delta_{0}$ \\
\hline \multirow{2}{*}{$\begin{array}{c}\text { EDC }+ \text { wollastonite } \\
\quad \mathrm{d} \leq 0,1\end{array}$} & 1.26 & 0.29 & 0.19 & 1.85 & 0.28 & 0.34 \\
\hline & $\overline{0.11}$ & $\overline{0.30}$ & $\overline{0.18}$ & $\overline{0.72}$ & 0.30 & $\overline{0.31}$ \\
\hline \multirow{2}{*}{$\begin{array}{c}\text { EDC + wollastonite } \\
\qquad \mathrm{d} \leq 0.05\end{array}$} & 1.31 & 0.30 & 0.18 & 1.88 & 0.29 & 0.35 \\
\hline & 0.21 & 0.31 & 0.17 & 0.79 & 0.32 & 0.31 \\
\hline \multirow{2}{*}{$\begin{array}{c}\text { EDC + wollastonite } \\
\mathrm{d} \leq 0.005\end{array}$} & 1.81 & $\underline{0.32}$ & $\underline{0.19}$ & 2.19 & $\underline{0.29}$ & $\underline{0.36}$ \\
\hline & $\overline{0.30}$ & $\overline{0.33}$ & 0.19 & 0.90 & 0.34 & 0.35 \\
\hline
\end{tabular}

Note: EDC -Epoxy Diane compound; the content of the wollastonite filler of dispersion $(d)$ in the epoxy composition in all cases is 60 weight parts; in the denominator for refined cotton (with watersoluble polymer composition based on carboxymethyl cellulose); $\delta_{0}$ is the relative damageability of cotton.

It should be noted that the larger the size of the filler particles, the better the triboparameters of composite polymeric materials with cotton. This is due to the improvement in the physical and mechanical properties and structure of composite coatings.

Therefore, it is of interest to determine the required minimum content of fillers of a laminar structure, realizing the effect of cleavability. For this purpose, and to study the distribution of particles over the coating thickness, we conducted special experiments using a lamellar graphite filler at its various contents while determining the electrical resistance of the polished surface of the coatings $\left(\rho_{\mathrm{s}}\right)$, identifying them as running-in surfaces under frictional interaction (Table 2). It is seen that the surface electrical conductivity changes in different ways, not only depending on the content but also on the method of getting the coating. The values of $1 / \rho_{\mathrm{s}}$ of epoxy coatings obtained with the method proposed by the authors [14] (the formation of the coating occurs in an overturned top layer) intensively increase with an increase in the graphite content up to 5 weight parts, regardless of the level of the polished surface layer of the coatings. A further increase in the graphite content up to $40 \mathrm{pbw}$, although accompanied by a monotonic increase in $1 / \rho_{\mathrm{s}}$, does not significantly differ in their value depending on the filler content. $1 / \rho_{\mathrm{s}}$ of coatings formed by the traditional method increases monotonically with an increase in the filler content and substantially differs in intensity depending on the level of the polished surface layer; a more intense increase is observed at grinding levels close to the substrate.

Modified compositions of composite materials [15] based on epoxy resin and mineral fillers can be used in various equipment to protect them from corrosion and wear [17]. At the same time, carbon black [18] or modified metal-polymer composites [19] can be used as a protective agent of the set destruction process and improve the surface electrical conductivity. 
Table 2. Influence of the method of formation and content of graphite filler on the surface conductivity of epoxy coatings across its thickness at different levels of grinding

\begin{tabular}{|c|c|c|c|c|c|c|}
\hline \multirow{2}{*}{$\begin{array}{l}\text { The level of the } \\
\text { surface section (along } \\
\text { with the thickness } \\
\mathrm{h}^{* *}, \mu \mathrm{m} \text { ) of the } \\
\text { coatings }\end{array}$} & \multicolumn{6}{|c|}{$\begin{array}{c}\text { Surface conductivity }(-) \cdot \lg \left(1 / \rho_{\mathrm{s}}\right) \\
\mathrm{Ohm}^{-1} \text { at various contents of graphite weight parts* }\end{array}$} \\
\hline & 1.0 & 2.5 & 5.0 & 10 & 20 & 40 \\
\hline 100 & $11.8 / 9.2$ & $9.4 / 5.6$ & $7.3 / 4.6$ & $6.4 / 3.7$ & $5.2 / 2.4$ & $3.2 / 2.5$ \\
\hline 400 & $11.6 / 8.9$ & $8.1 / 5.5$ & $6.4 / 4.9$ & $6.3 / 3.6$ & $4.6 / 2.5$ & $2.6 / 2.4$ \\
\hline 800 & $10.2 / 8.8$ & $6.9 / 5.7$ & $5.5 / 4.8$ & $4.5 / 3.7$ & $3.7 / 2.3$ & $1.89 / 1.8$ \\
\hline 1200 & $8.8 / 8.7$ & $5.8 / 5.5$ & $4.7 / 4.8$ & $3.9 / 3.7$ & $2.4 / 2.4$ & $1.8 / 1.9$ \\
\hline
\end{tabular}

As the results of the study, it was established that the considered pattern (formulas 1 8), to a certain extent, has general adequacy to research results [20]-[22], taking into account the relaxation of mechanical stress; that is, the variability of deformation over time is associated with relaxation processes, the only difference is that, in our case, the counterbody presents a highly deformable fibrous mass.

\section{Conclusions}

The research conducted and the results obtained led to the following conclusions:

- the traditional method of getting composite epoxy coatings does not allow achieving an optimal surface structure due to the non-uniform distribution of electrically conductive filler particles over the coating thickness due to their settling under the influence of gravity force from their own mass;

- the effect of cleavage of layered fillers can be realized even at contents of 5-10 parts by weight;

- for an antistatic purpose, 2-3 parts by weight of an electrically conductive filler of a laminar structure are sufficient, providing adequate surface conductivity, which is a channel for entropic signals of structural self-organization;

In the polymer-cotton tribosystem after the end of non-stationary friction, i.e. during the running-in period under stable frictional interaction, the formation of dynamic tribostructures continuously arises, providing a certain stable and minimum value of the friction force. The destruction of these tribostructures is compensated by their restoration, owing to information feedback, which are channels for transferring energy (entropy) signals; the density of triboelectric charge and temperature in the friction zone can be used as these signals.

\section{References}

1. Abdullah I., Blackburn R.S., Russell S.J., Taylor J. Abrasion phenomena in twill Tencel fabric. Journal of Applied Polymer Science. pp. 1391-1398. DOI:10.1002/app.24195. (2006)

2. Das A., Kothari V.K., Vandana N. A study on frictional characteristics of woven fabrics. Autex Research Journal. pp. 133-140. (2005)

3. Zhang Z., Fletcher I.W., Hurley C.R., Boardman C., Doyle P., Leggett G.J. Morphological and quantitative frictional measurements of cotton fibres using friction force microscopy. Journal of Materials Chemistry. 2010. DOI:10.1039/c0jm01362e. 
(2010)

4. Djumabaev, A.B. Friction and damage to cotton. Tashkent, STANDART, p. 275.(2011)

5. Negmatov N.S., Ziyamukhamedova U.A., Kuluev A.R. Antifriction materials and water-soluble compounds on basis of polymers for reducing the mechanical damage of cotton fibers. Plasticheskie Massy: Sintez Svojstva Pererabotka Primenenie, pp. 4245, (2002)

6. Makhkamov R.G. Role of wax substances on fibres during interaction with machine surfaces. Izvestiya of Higher Educational Institutions, Ser. Textile Industry Technology. (2). pp. 101-104, (2006).

7. Negmatov S.S. Fundamentals of processes of contact interaction of composite polymer materials with fibrous mass, p. 296, Tashkent, (1984)

8. Hosseinali F., Thomasson J.A. Multiscale frictional properties of cotton fibers, A review (2018).

9. Wakelyn P.J. Cotton Fiber Chemistry and Technology, (2006).

10. Ziyamukhamedova U.A., Bakirov L.Y., Rakhmatov E.A., Bektemirov B.S. Structure and properties of heterocomposite polymeric materials and coatings from them obtained by Heliotechnological method, International Journal of Recent Technology and Engineering, (2019), doi:10.35940/ijrte.C1085.1083S19

11. Kurbanov M.Sh., Abdurakhmanov B.M., Ashurov H.B. Prospects for the development of silicon production and solar energy products in the Republic of Uzbekistan. Applied Solar Energy, 54 (2), pp. 85-90, USA. (2018)

12. Abdurakhmanov B.M., Ashurov H.B., Kurbanov M.S., Nuraliev, U.M. Modernization of the technology for obtaining technical silicon for solar energy. Applied Solar Energy (English translation of Geliotekhnika). pp. 282-286. doi:10.3103/S0003701X14040045. (2014).

13. Abdurakhmanov B.M., Adilov M.M., Ashurov K.B., Kurbanov M.S. Converters of the Thermal Component of Concentrated Solar Radiation Based on Granular Silicon. Applied Solar Energy (English translation of Geliotekhnika). pp. 257-262. (2020), DOI:10.3103/S0003701X20040039

14. Ziyamukhamedova U.A., Shaymardanov B.A. Mechanical and chemical method of modification while developing new composition materials based on epoxy binder and natural minerals. Bashkiria Chemistry journal, 19 (2). pp. 53-57, Ufa, (2012)

15. Ziyamukhamedova U., Djumabaev D., Shaymardanov B. Mechanical chemical modification method used in the development of new composite materials based on epoxy binder and natural minerals. Turkish journal of Chemistry, 37(1), pp. 51-56. Ankara (Turkey), (2013).

16. Yusupbekov A.K., Ibadullaev A., Abdurashidov T.R., Akhmedov K.S. International Symposium on Flow-Induced Vibration and Noise. Acoustic Phenomena and Interaction in Shear Flows over Compliant and Vibrating Surfaces. (6), Doklady. Chemical technology, pp. 79-80. (1988)

17. Bozorov O.N. Rakhmatov E.A. Dustkobilov E.N. Ziyamukhamedova U.A. Creation and application of corrosion-resistant coatings on the basis of modified local Angren kaolins and epoxy compounds, Journal of critical reviews, 7(16), pp. 2945-2950. (2020)

18. Ibadullaev A., Yusupbekov A.K., Gorbunov V.A., Abdurashidov T.R. Reactivity Of A Secondary Carbonaceous Raw Material With Respect To Carbon Dioxide. Journal of applied chemistry of the USSR, pp. 2387-2389, (1986)

19. Umarov A. V., Abdurakhmanov U., Khamzayev H.E., Kattaev N.T., Tozhiboev A.G. Synthesis and Structural Investigations of Metal-Containing Nanocomposites Based on Polyethylene. Zeitschrift fur Naturforschung - Section A Journal of Physical 
Sciences, pp. 183-187, (2019), doi:10.1515/zna-2018-0332.

20. Mirsaidov M.M., Sultaov T.Z., Rumi D.F. An assessment of dynamic behavior of the system "structure - Foundation" with account of wave removal of energy. Magazine of Civil Engineering, 39(4), pp. 94-105, (2013), doi: 10.5862/MCE.39.10

21. Mirsaidov M., Mekhmonov Y. Nonaxisymmetric vibrations of axisymmetric structures with associated masses and hollows (protrusions). Strength of Materials. pp. 424-430. (1987), DOI:10.1007/BF01524147.

22. Mirsaidov M.M., Sultanov T.Z. Assessment of stress-strain state of earth dams with allowance for non-linear strain of material and large strains. Magazine of Civil Engineering. pp. 73-82, (2014), doi:10.5862/MCE.49.8.

23. Kattakulov F., Muslimov T., Khusainov A., Vokhidov O., Sultanov S. Water resource saving in irrigation networks through improving the efficiency of reinforced concrete coatings, IOP Conference Series: Materials Science and Engineering, 883(1), 012053, (2020)

24. Rybakov V., Jos V., Raimova I., and Kudryavtsev K. Modal analysis of frameless arches made of thin-walled steel profiles. IOP Conf. Ser. Mater. Sci. Eng. 883, (2020).

25. Khasanov B., Irmuhamedova L., Firlina G., Mirzaev T. Theoretical foundations of the structure formation of cement stone and concrete, IOP Conference Series: Materials Science and Engineering, 869(3), 032032, (2020)

26. Khasanov B., Vatin N., Mirzaev T., Suyunov A., Radjabov M. Physicochemical fundamentals of modifying concrete mix and concrete, IOP Conference Series: Materials Science and Engineering, 1030(1), 012022, (2021) 